\title{
PERMEN DAN JELLI SEBAGAI PRODUK INOVASI DARI PASAK BUMI (Eurycoma longifolia Jack)
}

\section{Candy and Jelly as Inovative Product of Pasak Bumi (Eurycoma longifolia Jack)}

\author{
Fatmir Edwar \\ Balai Riset dan Standardisasi Industri Banjarbaru \\ JI. Panglima Batur Barat No. 2 Telp./Fax. 0511-4772461/0511-4772115 Banjarbaru \\ e-mail: baristand.banjarbaru@gmail.com
}

Diterima: 5 Juni 2015, revisi akhir: 10 Juni 2015 dan disetujui untuk diterbitkan: 12 Juni 2015

\begin{abstract}
ABSTRAK
Pasak bumi (Eurycoma longifolia Jack) merupakan salah satu jenis tumbuhan hutan tropis di Indonesia yang pemanfaatannya sebagai bahan baku dalam pembuatan obat baik yang modern maupun tradisional. Pasak bumi mengandung senyawa erikomanon yang ampuh mengobati malaria dan senyawa kuasinoid serta alkaloid yang dapat menghambat pertumbuhan sel kanker. Pasak bumi juga mempunyai senyawa aktif flavonoid yang berfungsi untuk melindungi struktur sel, meningkatkan efektifitas vitamin C, anti inflamasi, mencegah keropos tulang, antioksidan, dan antibiotik. Penelitian ini bertujuan untuk membuat produk permen dan jelli dari bagian akar, batang, daun, ranting, dan kulit pasak bumi sehingga dapat meningkatkan nilai tambah dan memudahkan akses bagi masyarakat luas untuk mendapatkan khasiat zat aktif yang dikandung tumbuhan tersebut dalam bentuk produk inovatif. Standard produk yang dihasilkan (permen dan jelli) mengacu kepada SNI 3547.1:2008 tentang kembang gula keras dan SNI No. 3547.2:2008 tentang kembang gula lunak. Berdasarkan hasil pengujian permen, semua parameter yaitu kadar air, abu, gula, sukrosa, $\mathrm{Zn}, \mathrm{Hg}, \mathrm{Pb}$, As, Angka Lempeng Total, Coliform, Ecoli, Salmonella dan Kapang/Khamir memenuhi syarat, kecuali untuk parameter $\mathrm{Cu}$ dengan nilai antara 3,48-8,17\% tidak memenuhi standar yang dipersyaratkan yaitu maksimal $2 \%$. Sedangkan produk jelli sebagian besar memiliki kadar air bervariasi antara 18,20-39,45\% tidak memenuhi standar yang dipersyaratkan maksimal $20 \%$. Hasil dari penelitian ini dapat meningkatkan nilai tambah dan nilai jual dari tumbuhan pasak bumi berupa produk permen dan jelli yang memiliki cita rasa, keunggulan dan manfaat bagi kesehatan.
\end{abstract}

\section{Kata Kunci: Pasak bumi, ekstraksi, permen, jelli, Eurycoma longifolia Jack}

\begin{abstract}
Pasak bumi is one type of tropical forest herb in Indonesia that is used for raw material of both the manufacture of modern and also traditional medicine. Pasak bumi compound concists of erikomanon that potent to treat malaria, kuasinoid, and alkaloid that can inhibit the growth of cancer cells. Pasak Bumi also has an active flavonoid compound that is useful to protect the cell structure, improve the effectiveness of vitamin $C$, anti-inflammatory, prevent bone loss, antioxidant and antibiotic. This research aims to make candy and jelly products from the roots, stems, leaves, twigs and bark of Pasak Bumi (Eurycoma longifolia Jack) so that it can increase the added value and make easy of access for the public to get the properties of the active substance that contained in the plant in the form of products innovative. Standard of products (candy and jelly) were based on Indonesian National Standard Number 3547.1:2008 for hard candy and Indonesian National Standard nomber 3547.2:2008 for soft confectionery. Tested of candy, all parameters of water content, ash, sugar, sucrose, $\mathrm{Zn}, \mathrm{Hg}, \mathrm{Pb}$, As, total plate count, coliform, E coli, salmonella and fungi/yeast number are according to standard, except parameter of Cu was between 3.48 to $8.17 \%$. It did not appropriate to the standard, where the maximum is $2 \%$. While the majority of jelly water content parameters were varies from 18.20 to $39.45 \%$, it did
\end{abstract}


not fulfill the maximum standard that is $20 \%$. The result of this research can increase the value added and sale value of pasak bumi plant in form of candy and jelly that have a taste, excellence and health benefit.

\section{Keywords: Pasak bumi, extraction, candy, jelly, Eurycoma longifolia Jack}

\section{PENDAHULUAN}

Indonesia merupakan negara tropis dan memiliki banyak jenis tumbuhan, tidak kurang dari 30.000 jenis yang tersebar di seluruh kepulauan Indonesia. Dari berbagai jenis tumbuhan tersebut $25 \%$ merupakan tumbuhan obat (Imran et al., 2010). Pemanfaatannya digunakan sebagai bahan baku dalam pembuatan obat baik yang modern maupun tradisional yang berasal dari daun, batang, buah, bunga dan akar (Crisnaningtyas, 2010). Jenis tumbuhan obat hutan tropis Indonesia yang banyak digunakan dalam pembuatan obat antara lain adalah pasak bumi (Eurycoma longifolia Jack). Kalimantan Selatan merupakan salah satu daerah yang sangat kaya akan sumber daya alam berupa bahan baku obat-obatan, disamping tumbuhan pasak bumi, ada beberapa tumbuhan seperti tabat barito yang banyak dikirim ke beberapa negara (Rosehan, 2012).

Pasak bumi yang merupakan salah satu jenis tumbuhan obat dan telah dikenal di Kalimantan sejak jaman dahulu dan memiliki berbagai khasiat. Akar pasak bumi mengandung senyawa erikomanon yang ampuh mengobati malaria. Senyawa kuasinoid dapat melumpuhkan Plasmodium falcifarum yaitu bakteri yang hidup dalam tubuh nyamuk Anopiles betina penyebab penyakit malaria. Senyawa kuasinoid dan alkaloid yang terkandung dalam pasak bumi dapat menghambat pertumbuhan sel kanker (Khanam et al., 2014). Pasak bumi disamping mempunyai senyawa kuasinoid dan alkaloid seperti yang telah dikemukakan diatas juga mempunyai senyawa aktif flavonoid yang berfungsi untuk melindungi struktur sel, meningkatkan efektifitas vitamin C, anti inflamasi, mencegah keropos tulang, antioksidan dan antibiotik (Muhammad, 2011). Demikian juga menurut Kosala (2010), bahwa pasak bumi dapat menyembuhkan penyakit kencing manis, liver, impotensi, reumatik, asam urat, mengobati gangguan pencernaan dan meningkatkan vitalitas.

Produk olahan dari pasak bumi dapat dikembangkan menjadi beberapa inovasi antara lain kopi pasak bumi, pasak bumi instan, permen pasak bumi, jelli pasak bumi dan sebagainya. Berdasarkan hal tersebut diatas, maka dilakukan penelitian yang berkaitan dengan tumbuhan Pasak Bumi (Eurycoma longifolia Jack). Penelitian ini bertujuan untuk membuat produk permen dan jelli dari bagian akar, batang, daun, ranting dan kulit pasak bumi sehingga dapat meningkatkan nilai tambah dan memudahkan akses bagi masyarakat luas untuk mendapatkan khasiat zat aktif yang dikandung tumbuhan tersebut dalam bentuk produk inovatif.

\section{METODOLOGI PENELITIAN}

Bahan yang digunakan adalah bagian akar, batang, ranting, kulit dan daun pasak bumi, gula pasir, flavour makanan, natrium benzoate, asam sitrat, sirup glukosa, gelatin, agar-agar, air, gula pasir, gula halus, flavour mint, karagenan dan etanol. Sedangkan peralatan yang digunakan berupa timbangan, gelas ukur, thermometer, kompor, kertas saring, pengaduk, pisau, blender, plastik, sarung tangan, toples dan alat cetak permen/jelli.

\section{Cara Kerja}

Masing-masing bagian tumbuhan pasak bumi dicuci sampai bersih, dikeringkan dan dihancurkan dengan blender. Setelah hancur dilarutkan dengan air dan dimasak sampai mendidih kemudian diaduk selama 3 jam dan dilakukan penyaringan. Filtrat yang diperoleh, kemudian dipekatkan dengan rotary evaporator pada suhu $40^{\circ} \mathrm{C}$ hingga didapatkan filtrat pekat yang siap untuk dibuat permen dan jelli pasak bumi. 


\section{Pemasakan Permen}

Gula pasir, perasa makanan, natrium benzoate, sirup glukosa dan asam sitrat dicairkan dalam wajan dengan api sedang ( \pm $50^{\circ} \mathrm{C}$ ). Setelah gula mulai mencair, ekstrak pasak bumi dimasukkan sambil diaduk-aduk hingga terbentuk karamel (suhu $\pm 156^{\circ} \mathrm{C}$ ). Jika sudah terbentuk karamel kemudian dituangkan dalam cetakan permen dengan cepat dan dikeringkan.

\section{Pemasakan Jelli}

Proses pembuatan jelli sama dengan pembuatan permen, hanya pada pembuatan jelli ditambah bahan pengental yaitu gelatin, karagenan, agar-agar yang sebelumnya dilarutkan dengan air panas sambil diaduk hingga mengental. Adonan yang sudah menjadi gel tersebut dituangkan dalam cetakan. Selanjutnya dibiarkan selama 1530 menit dalam suhu ruangan.

\section{Pendinginan}

Pendinginan merupakan proses perlakuan agar permen atau jelli menjadi dingin. Maksud dari pendinginan tersebut adalah mempermudah pada saat pengeluaran permen atau jelli dari cetakan dan tidak merusak bentuk.

\section{Tahap Pengemasan}

Permen atau jelli pasak bumi yang sudah dicetak kemudian dikemas dalam plastik dengan menutup rapat atau mempress-nya supaya tidak ada udara yang masuk, kemudian disimpan dalam wadah atau toples yang rapat.

\section{Analisis dan Pengujian}

Desain penelitian yang digunakan yaitu menggunakan rancangan acak lengkap dengan tiga kali ulangan. Faktor perlakuan yang digunakan yaitu konsentrasi ekstrak pasak bumi $5 \%$, 10\% dan 15\% dengan waktu pemasakan bahan baku pasak bumi 1 jam, 2 jam, dan 3 jam. Eksrak yang digunakan adalah dari bagian akar, batang, daun, kulit, dan ranting pasak bumi.
Produk permen dan jelli diuji kualitasnya berdasarkan SNI 3547.1.2008 tentang kembang gula keras dan SNI 3547.2.2008 tentang kembang gula lunak, yang meliputi kadar air, kadar abu, kadar gula, sakarosa, logam ( $\mathrm{Cu}, \mathrm{Hg}, \mathrm{Pb}, \mathrm{As}$ ) dan cemaran mikroba mikroba (Angka Lempeng Total, Coliform, E coli, Salmonella dan Kapang/Khamir).

\section{HASIL DAN PEMBAHASAN}

Hasil pengujian permen dan jelli pasak bumi berdasarkan SNI 3547.1:2008 dan SNI 3547.2:2008 dengan berbagai perlakuan ditampilkan dalam bentuk grafik.

\section{Kadar air}

Kadar air merupakan salah satu parameter dari produk yang disyaratkan dalam SNI untuk kembang gula keras ataupun lunak. Berdasarkan hasil dari pengujian kadar air permen dan jelli pasak bumi dari bagian akar, batang, daun, kulit dan ranting dengan berbagai perlakuan dapat dilihat pada Gambar 1 .

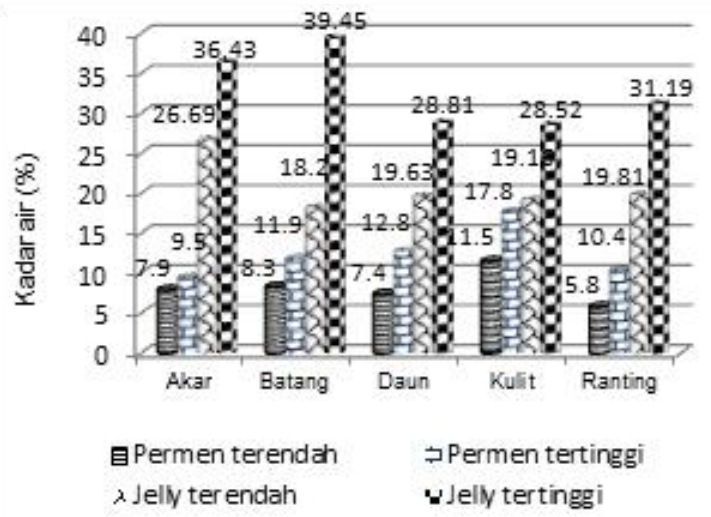

Gambar 1. Grafik hasil pengujian kadar air permen dan jelli pasak bumi

Pada Gambar 1 terlihat bahwa kadar air pada permen bagian akar bervariasi $0,79-0,95 \%$ dan pada jelli $26,69-36,43 \%$. Pada bagian batang untuk permen 0,83-1,19\% dan jelli 18,20-39,45\%. Bagian daun kadar air permen berkisar 0,74-1,28\% sedangkan jelli 19,65-28,81\%. Pada kulit produk permen berkisar 1,15-1,78\% dan jelli 
19,16-28,52\%. Untuk ranting kadar air berkisar 0,58-1,54\% dan jelli 19,81-29,97\%. Hasil tersebut menunjukkan bahwa produk permen dan jelli dari bagian akar, batang, daun, ranting dan kulit menghasilkan kadar air yang bervariasi. Semua perlakuan tidak berpengaruh nyata terhadap kadar air untuk masing masing bagian pasak bumi baik pada taraf nyata $5 \%$ maupun $1 \%$, ini dibuktikan dari F Hitung $>\mathrm{F}$ Tabel $5 \%$ dan $1 \%$.

Nilai kadar air lebih rendah pada permen dibandingkan dengan jelli pasak bumi. Hal tersebut disebabkan produk jelli pasak bumi berbentuk gel atau lunak sehingga masih banyak mengandung air dan kurangnya tingkat penyerapan air. Demikian juga dalam proses pembuatan produk jelli menggunakan bahan penolong agar-agar yang berbentuk gel sehingga kadar airnya menjadi tinggi. Menurut Winarno (2004) bahwa dalam pembuatan jelli menggunakan agar-agar yang berfungsi sebagai pembuat gel, penstabel, pengemulsi, pengisi, penjernih dan digunakan juga oleh industri makanan untuk meningkatkan viscositas serta dalam pembuatan fruitjelli, berbeda dengan produk permen yang berbentuk keras yang tingkat penyerapan airnya lebih tinggi. Kadar air merupakan salah satu komponen yang penting dalam bahan makanan karena air dapat mempengaruhi kenampakan, tekstur serta cita rasa makanan. Kandungan air dalam bahan permen dan jelli tersebut umumnya sangat menentukan terhadap mutu bahan permen dan jelli itu sendiri.

Berdasarkan hasil pengujian kadar air maka produk permen untuk semua kombinasi perlakuan antara konsentrasi ekstrak dan lama waktu perendaman memenuhi standar mutu SNI untuk kembang gula keras (max. 3,5\%), sedangkan produk jelli belum memenuhi standar mutu untuk kombinasi perlakuan extrak 5\% (1 jam) dengan nilai rata-rata $31,71 \%$. Sedangkan menurut SNI untuk kembang gula lunak kadar air maksimal yang dipersyaratkan maksimal $20 \%$.

\section{Kadar abu}

Hasil dari pengujian kadar abu produk permen dan jelli pasak bumi untuk masing- masing kombinasi perlakuan bervariasi, pada bagian akar untuk permen rata-rata berkisar antara 0,05-0,07\%, jelli antara $0,09-0,11 \%$. Untuk bagian batang rata-rata menghasilkan antara $0,05-0,06 \%$ dari permen dan jelli $0,06-0,11 \%$. Bagian daun berkisar antara 0,05-0,09\% sedangkan untuk jelli 0,08-0,12\%. Bagian kulit berkisar antara $0,03-0,06 \%$ untuk permen dan jelli berkisar $0,11-0,18 \%$. Demikian juga pada bagian ranting antara 0,03-0,06\% untuk permen dan pada jelli berkisar antara $0,06-0,11 \%$. Berdasarkan uji statistik, semua perlakuan tidak berpengaruh nyata terhadap kadar abu untuk masing-masing bagian pasak bumi baik pada taraf 5\% maupun $1 \%$, ini dibuktikan dari nilai F Hitung $>\mathrm{F}$ tabel $5 \%$ dan 1\%. Hasil rata-rata kadar abu dapat dilihat pada Gambar 2.

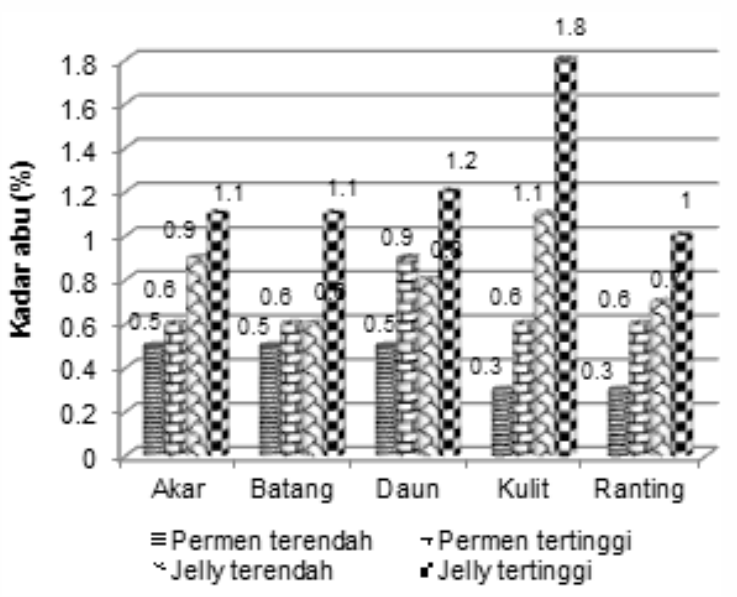

Gambar 2. Grafik hasil pengujian kadar abu permen dan jelli pasak bumi

Bervariasinya kadar abu pada produk permen dan jelli pasak bumi adanya kandungan mineral dari pasak bumi dan bahan baku dalam proses pembuatan permen dan jelli. Produk hasil penelitian menunjukkan nilai kadar abu yang tertinggi pada produk jelli pasak bumi baik pada konsentrasi ekstrak 5\%, 1\% maupun 15\% dengan lama ekstrak 1 jam, 2 jam dan 3 jam. Secara kimia abu dapat didefinisikan sebagai oksida logam dan bahan-bahan lain yang tidak dapat dibakar yang merupakan komponen hara tumbuhan dan komponen molekul penting dalam reaksi biokimiawi tumbuhan. Menurut Merynda et al., (2010) 
bahwa kadar abu sangat berhubungan dengan bahan mineral yang merupakan penambahan bahan organik sehingga akan meningkatkan kadar abu pada bahan tersebut. Demikian juga menurut Winarno (2004), kandungan bahan organik dan air sebagian besar bahan makanan hampir $96 \%$ dan sisanya terdiri dari unsur-unsur mineral, unsur mineral juga dikenal dengan zat anorganik atau kadar abu.

Berdasarkan pengujian kadar abu produk permen dan jelli pasak bumi yang dihasilkan dalam penelitian ini untuk semua kombinasi perlakuan antara konsentrasi ekstrak dan lama waktu pemasakan telah sesuai dengan standar mutu SNI 3547.1:2008 dan SNI 3547.2:2008 tentang kembang gula keras dan lunak yang mengsyaratkan maksimal $2,0 \%$ untuk permen dan maksimal $3 \%$ untuk jelli.

\section{Kadar gula}

Berdasarkan hasil pengujian dari produk permen dan jelli pasak bumi dapat dikemukakan bahwa kadar gula hasil penelitian sangat bervariasi dan ada perbedaan hasil pengujian antara produk permen dan jelli, seperti pada Gambar 3.

Kadar gula bagian akar untuk semua kombinasi perlakuan pada permen berkisar antara 23,37-43,59\% dan jelli 5,94-10,42\%, batang pada permen antara 16,10-23,71\% dan jelli $8,39-11,37 \%$. Untuk bagian daun produk permen antara 17,09-28,90\% dan jelli antara 8,29-10,17\%. Pada bagian kulit produk permen antara 15,97-27,01\% dan jelli antara 3,69-10,42\%. Sedangkan ranting kadar gula untuk permen antara $21,62-29,22 \%$ dan jelli antara 8,43-11,25\%.

Dari hasil pengujian kadar gula permen pasak bumi, ada beberapa kombinasi perlakuan yang memenuhi standar yaitu $5 \%$ (1 jam) dengan nilai rata-rata $23,64 \%$, kombinasi $5 \%$ (2 jam) dengan nilai rata-rata $23,67 \%$ dan kombinasi 15\% (1 jam) dengan rata-rata kadar gula $22,73 \%$ dimana menurut SNI 3547.1:2008, kadar gula yang dipersyaratkan maksimal 24\%. Sedangkan untuk produk jelli semua perlakuan memenuhi standar mutu yang di persyaratkan maksimal $25 \%$.

Rata-rata kadar gula dari produk permen ternyata lebih tinggi daripada produk jelli dan hasil pengujian dapat dilihat pada
Gambar 3. Hal tersebut dipengaruhi oleh pemasakan bahan dan suhu (temperatur) dalam proses pembuatan permen sehingga bervariasinya hasil pengujian kadar gula. Hal tersebut sependapat dengan Widawati (2010) yang menyatakan bahwa faktor yang mempengaruhi hasil permen jelli antara lain penambahan gula, penggunaan pengenyal, pemasakan dan pendinginan.

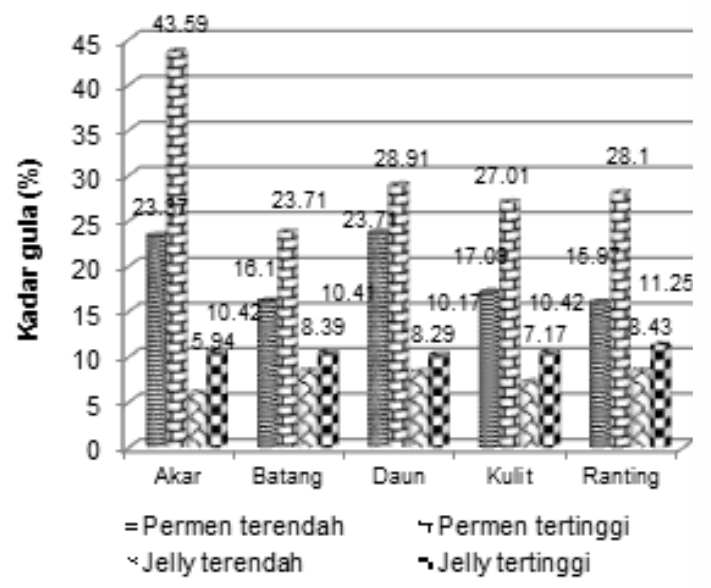

Gambar 3. Grafik hasil pengujian kadar gula permen dan jelli pasak bumi

Kadar gula jelli pasak bumi masih lebih rendah jika dibandingkan dengan kadar gula permen pasak bumi. Rendahnya kadar gula yang terkandung dalam permen jelli diduga karena perlakuan blanching dalam larutan gula pada pembuatan jelli. Menurut Pujimulyani et al., (2009) perlakuan perebusan (blanching) dan perendaman dalam larutan air dapat menyebabkan aktivitas antioksidan sampel jelli semakin menurun. Hal ini karena semakin lama waktu perendaman maka semakin banyak larutan gula yang masuk dalam sampel, kondisi tekstur jelli yang lebih kenyal dapat menyebabkan proporsi antioksidan dan komponen aktif yang lain menurun.

\section{Kadar sakarosa}

Hasil pengujian kadar sakarosa pada produk permen dan jelli untuk semua kombinasi perlakuan antara persentase ekstrak dengan waktu perendaman dapat dilihat pada Gambar 4. Kadar sakarosa permen pada bagian akar 17,16-22,19\%, jelli $11,14-18,51 \%$. Pada bagian batang produk permen $11,81-25,81 \%$. Bagian daun 
untuk produk permen berkisar $18,41-28,14 \%$ dan jelli 14,39-19,49\%. Sedangkan pada kulit untuk produk permen $12,51-21,64 \%$ dan ranting 18,97-26,13\% dan produk jelli berkisar 14,33-18,09\% dan ranting $12,64-22,78 \%$.

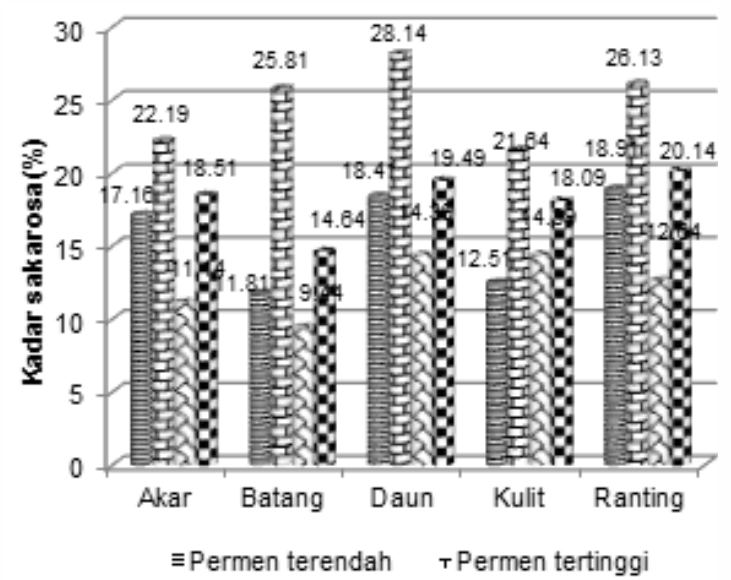

Gambar4. Grafik hasil pengujian kadar sakarosa permen dan jelli pasak bumi

Hasil pengujian kadar sakarosa permen dan jelli pasak bumi menunjukkan nilai yang bervariasi. Hal tersebut disebabkan dari perlakuan konsentrasi dan waktu ekstraksi terhadap bahan baku pasak bumi dari bagian pasak bumi (akar, batang, kulit, ranting, daun). Penggunaan bahan ekstrak yang terlalu banyak akan mempengaruhi kadar sakarosa, seperti diketahui bahwa pasak bumi terdiri dari beberapa senyawa aktif tumbuhan antara lain tanin, saponin, alkaloid, fenolik. Senyawa aktif tersebut memberi rasa pahit sehingga akan berpengaruh terhadap kadar sakarosa produk permen dan jelli yang dihasilkan. Berdasarkan uji statistik bahwa semua perlakuan tidak berpengaruh nyata terhadap kandungan sakarosa pada masing-masing bagian dari pasak bumi pada taraf $5 \%$ maupun $1 \%$, ini dibuktikan dari nilai F Hitung $>$ FTabel.

Berdasarkan hasil pengujian kadar sakarosa pada produk permen dan jelli pasak bumi untuk semua kombinasi perlakuan belum memenuhi standar mutu SNI permen keras dan lunak yang mensyaratkan minimum 35\%.

\section{Kadar Cu, Zn, Hg, Pb dan As}

Hasil pengujian produk permen dan jelli pasak bumi pada parameter $\mathrm{Cu}, \mathrm{Zn}, \mathrm{Hg}, \mathrm{Pb}$ dan As tersebut menunjukkan hasil yang bervariasi baik untuk produk permen maupun pada produk jelli. Hasil pengujian kadar $\mathrm{Cu}$ produk permen dan jelli untuk semua kombinasi perlakuan antara persentase ekstrak dan waktu perendaman adalah pada bagian akar berkisar antara $5,16-6,19 \%$ dan jelli 3,29-6,13\%, bagian batang untuk permen $5,17-8,17 \%$ dan jelli 2,34-4,95\%, bagian daun produk permen antara $4,41-7,12 \%$ dan jelli 4,87-5,80\%, pada kulit untuk permen antara 5,75-8,89\% dan jelli $3,09-4,81 \%$ sedangkan ranting untuk produk permen berkisar antara $3,48-5,16 \%$ dan untuk jelli $1,79-3,95 \%$. Menurut standar mutu SNI 3547.1:2008 dan SNI 3547.2:2008, berdasarkan pada Gambar 5 terlihat bahwa Kadar $\mathrm{Cu}$ pada produk permen dan jelli pada keseluruhan bagian dari pasak bumi yang dihasilkan belum memenuhi standar mutu kembang gula keras dan I unak yang mempersyaratkan maksimal $2 \%$.

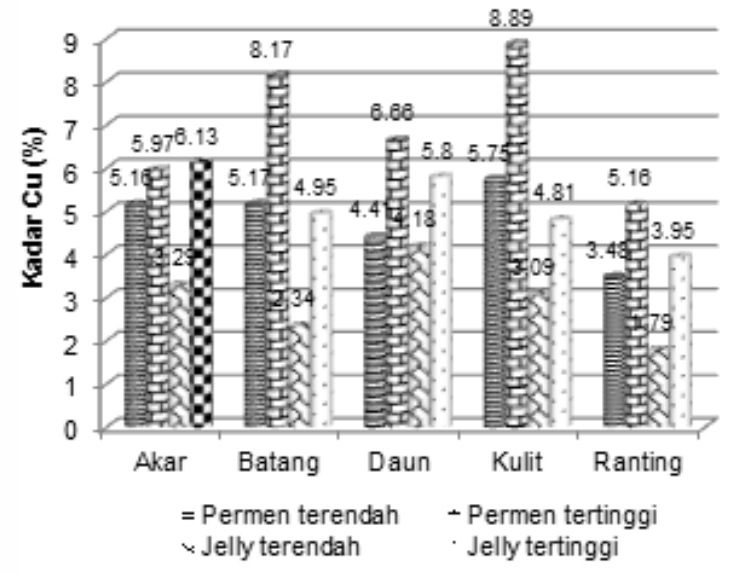

Gambar 5. Grafik hasil pengujian kadar $\mathrm{Cu}$ permen dan jelli pasakbumi

Pengujian kadar Zn untuk semua kombinasi perlakuan pada produk permen dimana bagian akar antara $0,93-2,86 \%$ dan jelli $1,11-1,93 \%$, bagian batang produk permen 1,05-2,17\% dan jelli 1,90-2,85\% untuk bagian daun antara $1,08-2,21 \%$ dan jelli $1,18-2,22 \%$. Pada produk permen 
bagian kulit antara 1,96-2,70\% dan jelli $1,11-2,19 \%$, untuk ranting produk permen berkisar antara $1,12-2,07 \%$ dan jelli $1,43-2,24 \%$. Bervariasinya hasil produk permen dan jelli disebabkan oleh perbedaan bahan baku bagian dari pasak bumi yang terdiri dari batang, akar, ranting, kulit dan daun serta waktu proses ekstraksi dari pasak bumi. Untuk parameter uji Zn pada produk kembang gula keras dan lunak belum mempersyaratkan standar mutu sehingga produk permendan jelli pasak bumi tidak memacu pada standar mutu sesuai SNI 3547.1:2008 dan SNI 3547.2:2008.

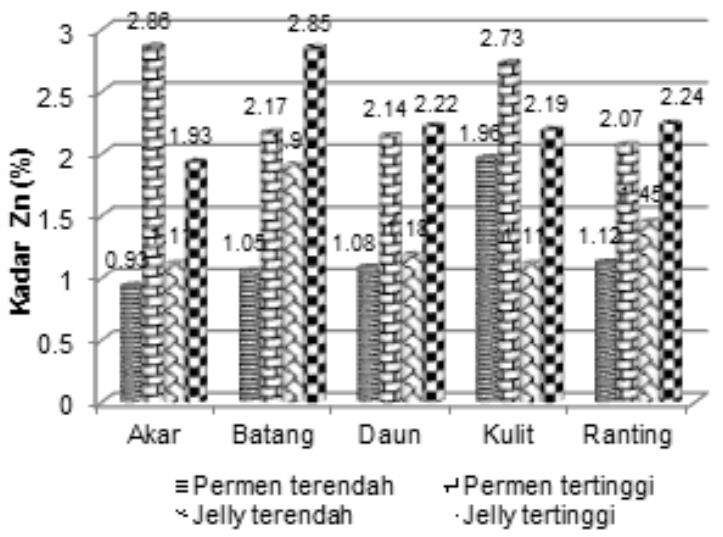

Gambar 6. Grafik hasil pengujian kadar Zn permen dan jelli pasak bumi

Pada pengujian kadar Cu permen dan jelli pasak bumi belum memenuhi standar mutu sesuai SNI kembang gula keras dan lunak, hal tersebut mungkin dari bahan baku yang digunakan (akar, batang, kulit, ranting dan daun pasak bumi) dan proses pembuatan permen dan jelli pasak bumi. Menurut Astawan (2008) bahwa kontaminasi logam berat berasal dari udara dan air yang mencemari tanah dan tanaman yang tumbuh di atas tanah yang telah tercemar akan mengakumulasikan logam-logam tersebut pada semua bagian akar, batang, daun dan buah. Selanjutnya Astawan (2008) menyatakan cemaran logam Cu pada bahan pangan pada awalnya terjadi karena penggunaan pupuk dan pestisida secara berlebihan. Meskipun demikian, pengaruh proses pengolahan akan dapat mempengaruhi status keberadaan tersebut dalam bahan pangan. Sedangkan hasil pengujian untuk parameter $\mathrm{Hg}, \mathrm{Pb}$ dan $\mathrm{As}$ untuk produk permen dan jelli memperoleh hasil $\pm 0,001 \mathrm{mg} / \mathrm{kg}$ untuk semua kombinasi perlakuan.

Hasil pengujian tersebut menunjukkan bahwa pengujian $\mathrm{Hg}, \mathrm{Pb}$ dan As memenuhi standar mutu SNI kembang gula keras dan lunak dmana untuk kadar Hg pada permen dipersyaratkan pada permen maksimum $<0,001$ dan jelly maksimum $<0,003-0,009 \%$. Persyaratan Kadar $\mathrm{Pb}$ untuk permen dan jelly maksimum $2,0 \%$ dan As maksimum $1,0 \%$ untuk permen dan jelly. Demikian juga dengan hasil pengujian cemaran mikroba yang meliputi Angka Lempeng Total (1,0 x $\left.10^{2}\right)$, Coliform $(<3)$, Ecoli $(<3)$, Salmonella (negatif) dan Kapang/Khamir $\left(1,0 \times 10^{2}\right)$ untuk produk permen dan jelli pasak bumi memenuhi persyaratan mutu pada semua kombinasi perlakuan sehingga aman untuk dikonsumsi.

\section{KESIMPULAN}

Berdasar hasil pengujian terhadap produk permen dan jelli dari tumbuhan pasak bumi pada bagian akar, batang, kulit, daun dan ranting menunjukkan hasil bahwa semua bagian dari tumbuhan pasak bumi dapat dibuat produk permen dan jelli pasak bumi dan memenuhi standar mutu SNI 3547.1:2008 kembang gula keras dan SNI 3547.2:2008 kecuali untuk parameter sakarosa dan $\mathrm{Cu}$ ( tidak memenuhi standar mutu). Sedangkan pada jelli pasak bumi yang belum memenuhi standar mutu kembang gula lunak yaitu parameter kadar air dengan konsentrasi ekstrak 5\% dan lama pemasakan 1 jam yang mempersyaratkan kadar air maksimal $20 \%$.

\section{DAFTAR PUSTAKA}

Astawan, M. 2008. Bahaya Logam Berat Dalam Makanan. Sehatnews.Com.

Badan Standardisasi Nasional. 2008. SNI 3547.1: 2008 Persyaratan Mutu Kembang Gula Keras. BSN, Jakarta.

Badan Standardisasi Nasional. 2008. SNI 3547.2:2008. Persyaratan Mutu Kembang Gula Lunak. BSN, Jakarta. 
Crisnaningtyas. 2010. Pemanfaatan sarang semut (Myrmecodia pendens) asal Kalimantan Selatan sebagai anti bakteri. Jurnal Riset Industri Hasil Hutan. Vol 2 No.2 Desember 2010, hal 32-36.

Imran, G. dan Lexie, P. Mamahit. 2010. Satu senyawa steroid dari kulit batang tumbuhan paliasa (Kleinhovia hospital L) asal Sulawesi Selatan. Jurnal Chemical Program Vol. 1 Mei 2010.

Khanam, Z., Chow, S. W., dan Irshat, U. H., Bhat. 2014. Phytochemical screening and antimicrobial activity of root and stem extracts of wild Eurycoma longifolia Jack (Tongkat Ali). Journal of King Sayd University Science.

Kosala, K. 2010, Uji efek proteksi akar pasak bumi (Eurycoma longifolia JACK) terhadap ulkus lambung tikus yang diinduksi dengan ligasi pilori. Media Sains, Vol 2, No 1.

Merynda, I. S., Eka, L., and Hendra. 2010. Karakteristik permen jelly timun suri (Cucumis melo L) dengan penambahan sorbitol dan ekstrak kunyit (Curcuma domestika Val). Jurnal Gizidan Pangan, 5(2):78-86.
Muhammad, A. 2011. Sarang semut dan buah merah pembasmi ragam penyakitganas. Yogyakarta. Laksana.

Sudjana. 1997. Desain dan analisis eksperimen. PT Tarsito Bandung.

Pujimulyani, D. dan Wazyka, A. 2009. Sifat antioksidasi, sifat kimia dan fisik manisan basah dari kunir putih (Curcuma mangga Val.). Jurnal Agri Technologi (AGRITECH). Vol. 29 (3) : 167-173.

Rosehan. 2012. Mengangkat potensi Kalimantan Selatan sebagai obat produsen obat herbal.

Widawati, L. 2010. Pembuatan permen dan jelli dari buah mengkudu (Morinda citrifolia) sebagai solusi alternatif pelestarian tanaman mengkudu.

Winarno. 2004. Kimia pangan dan gizi. PT Gramedia Pustaka Utama. Jakarta. 